\title{
United Arab Emirates
}

National Cancer Institute

\section{Source}

National Cancer Institute. United Arab Emirates. NCI Thesaurus. Code C17232.

A country in the Middle East, bordering the Gulf of Oman and the Persian Gulf, between Oman and Saudi Arabia. 